\title{
EMBALAGENS COMESTÍVEIS: APLICAÇÃO, EFEITO NA SEGURANÇA ALIMENTAR E ACEITABILIDADE
}

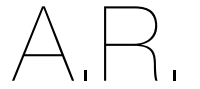

ARTIGO DE REVISÃO

1 Associação Portuguesa de Nutrição,

Rua João das Regras,

n. ${ }^{\circ} 278$ e $284, R / C 3$,

4000-291 Porto, Portugal

2 Escola Superior de Tecnologia da Saúde de Coimbra do Instituto Politécnico de Coimbra,

Rua 5 de Outubro, 3046-854 Coimbra Portugal

Endereço para correspondência:

Helena Real

Associação Portuguesa de

Nutrição,

Rua João das Regras, n. ${ }^{\circ} 278$

$284, \mathrm{R} / \mathrm{C3}$

4000-291 Porto, Portuga

henareal@apn.org.pt

Histórico do artigo

Recebido a 2 de fevereiro de 2021

Aceite a 27 de junho de 2021

\author{
EDIBLE PACKAGING: APPLICATION, IMPACT ON FOOD \\ SAFETY AND ACCEPTABILITY
}

RESUMO

O plástico é um material amplamente utilizado para o desenvolvimento de embalagens alimentares, no entanto a crescente preocupação com a sua natureza não bio-degradável e acumulativa nos ecossistemas, levou ao desenvolvimento de alternativas mais sustentáveis.

O presente artigo de revisão pretende caraterizar o impacto ambiental e tecnológico das embalagens comestíveis, a aplicabilidade, o tipo de matérias-primas utilizadas, as possíveis implicações na segurança alimentar, bem como explorar a aceitabilidade por parte dos consumidores e da indústria alimentar.

Esta revisão foi realizada nas bases de dados "Science Direct", "PubMed" e "Google Scholar" usando os descritores "edible", "food", "packaging", "coating" e "film". A partir da fonte mencionada, foram selecionados 56 artigos para o presente artigo de revisão, publicados entre 2015 e 2021.

Os materiais utilizados para produzir filmes e revestimentos comestíveis são geralmente biomoléculas e devem ser selecionadas tendo em vista o tipo de alimento a embalar. Além disso, não devem constituir nenhum risco para a saúde humana. Não obstante, as embalagens comestíveis podem conter alergénios, pelo que devem ser listados os ingredientes utilizados na elaboração destas embalagens. A aplicação de diferentes filmes e revestimentos, em uma variedade de alimentos, demonstrou aumentar o tempo de vida de prateleira dos géneros alimentícios. A aceitação das embalagens edíveis pelo consumidor depende de vários fatores tais como as propriedades funcionais e organoléticas, o marketing alimentar e os preços. A produção de filmes e revestimentos comestíveis ocorre maioritariamente à escala laboratorial, pelo que há algumas limitações a serem ultrapassadas, de forma a garantir o sucesso destes materiais à escala comercial. Atendendo ao objetivo previamente definido, foi possível caraterizar e explorar os conceitos e temas propostos.

\section{PALAVRAS-CHAVE}

Embalagens alimentares comestíveis, Filmes, Revestimentos, Segurança alimentar

ABSTRACT

Plastic is commonly used for the development of food packaging, however the growing concern with its non-biodegradable and accumulative nature in ecosystems, has led to the development of more sustainable alternatives.

The purpose of this review article is to characterize the environmental and technological impact of edible food packaging, their applicability, the type of raw materials used, the possible implications for food safety, as well as exploring the acceptability of consumers and the food industry.

This research was conducted in the databases "Science Direct", "PubMed" and "Google Scholar" using "edible", "food", "packaging", "film" and "coating" as keywords. From the mentioned source, 56 articles, from 2015 to 2021, were selected for this review.

The materials used to produce edible films and coatings are generally biomolecules and must be selected considering both their main characteristics and the type of food to be packaged. In addition, these materials should not pose any risk to human health. Regardless, edible packaging may contain allergens, thus the ingredients used in the preparation of these packaging must be listed. The application of different films and coatings, in a variety of foods, has been shown to increase the shelf life of foodstuffs. The acceptability of edible packaging by the consumer depends on several factors, such as functional and organoleptic properties, food marketing and prices. The production of edible films and coatings occurs mostly on a laboratory scale, so there are some limitations to overcome, in order to guarantee the success of these innovations on a commercial scale. According to the previous established aim, it was possible to explore the proposed concepts and themes.

KEYWORDS

Edible food packaging, Film, Coating, Food safety 


\section{INTRODUÇÃO}

As embalagens usadas na indústria alimentar têm como funcionalidades conter o alimento, protegê-lo de agentes de deterioração, tais como a luz, o calor, a humidade, os gases, e os microrganismos e consequentemente aumentar o seu tempo de vida de prateleira. Além disso, as embalagens visam informar o consumidor, através da rotulagem alimentar, bem como atraí-lo através de diversas estratégias de marketing usadas na própria embalagem (1-4).

Embora os polímeros derivados do petróleo, tais como o plástico, tenham sido amplamente usados com essa finalidade, a crescente preocupação com a sua natureza não biodegradável, e acumulativa nos ecossistemas, desencadeou a investigação e o desenvolvimento de alternativas mais sustentáveis, incluindo o uso de polissacarídeos e proteínas (2, 5-11). Estas biomoléculas, comummente extraídas de alimentos, como frutas e produtos hortícolas, quando submetidas a diversos processos tecnológicos, fornecem embalagens comestíveis com propriedades físico-mecânicas adequadas, bem como características sensoriais e nutricionais otimizadas $(5,6)$.

As embalagens comestíveis podem ser aplicadas aos alimentos na forma de revestimentos e filmes. Considera-se um revestimento comestível quando a solução que dá origem ao filme edível é aplicada diretamente no produto (12). Este procedimento pode ocorrer através da imersão do género alimentício (GA) na solução, ou através da aplicação da mesma sob a forma de spray ou com auxílio de um pincel (brushing). Após a deposição da solução na superfície do alimento, esta é submetida ao processo de secagem, de modo a formar uma película fina $(3,5,8,9,13-15)$.

Um filme comestível é uma solução, que é igualmente sujeita ao processo de secagem, sendo posteriormente utlizada e aplicada como um material autónomo e isolado ao $\mathrm{GA}$, no alimento $(3,5,8,12,14)$. De forma a ser considerada um filme comestível, a sua espessura deve ser inferior a $254 \mu \mathrm{m}(9,13,15)$.

Desta forma, o presente artigo de revisão pretende explorar mais sobre a aplicabilidade das embalagens comestíveis, o tipo de matérias-primas mais recomendáveis para a conservação de diferentes tipos de alimentos, bem como as implicações que podem ter na segurança alimentar. É ainda relevante, considerar os aspetos sensoriais, nutricionais destas embalagens e assegurar a sua sustentabilidade e aceitabilidade, por parte dos consumidores e da indústria alimentar.

\section{METODOLOGIA}

Esta revisão teve por base a pesquisa de artigos científicos nas bases de dados "Science Direct", "PubMed" e "Google Scholar", usando os descritores "edible", "food", "packaging", "film" e "coating". O limite temporal para a pesquisa dos artigos científicos foi de 6 anos, isto é, artigos publicados desde novembro de 2015 a março de 2021 resultando em um total de 1407 artigos, obtidos através da combinação dos descritores. Com base na análise do título e resumo, foram excluídos os artigos repetidos, bem como artigos que tinham uma abordagem mais específica em determinadas áreas de estudo, que não se consideravam tão relevantes para a elaboração desta revisão. Após a leitura e análise integral dos 86 artigos selecionados a priori, utilizaram-se 56 artigos para a elaboração do presente artigo de revisão.

\section{Contexto Histórico}

Filmes e revestimentos comestíveis têm sido usados há séculos para a conservação de alimentos, nomeadamente para evitar a perda de humidade e para criar uma superfície mais brilhante dos géneros alimentícios. Tais práticas foram aceites e realizadas, muito antes de se compreender a ciência que as sustenta, e continuam a ser uma opção viável para a preservação da qualidade e da segurança dos alimentos, nos dias de hoje $(16,17)$.

No século XII, frutas cítricas do sul da China eram preservadas e enviadas para o norte do país, em caixas, em que se colocava cera derretida sobre o alimento, e este era enviado em caravanas, que percorriam longas distâncias. Embora a sua qualidade não fosse aceitável na sociedade moderna, o método era bastante eficaz para a época e foi usado durante séculos por falta de outros processos mais eficientes. $\mathrm{Na}$ Europa, o processo era conhecido como "larding" - armazenamento de várias frutas em cera ou gordura para consumo posterior (16).

Mais tarde, no século XV, um filme comestível, Yuba, extraído através da fervura da bebida de soja foi usado no Japão para manter a qualidade dos alimentos e melhorar a sua aparência $(16,18)$.

\section{Inovação, Mercado Português e Mundial}

Nas últimas duas décadas ocorreu um aumento substancial da literacia científica na área das embalagens comestíveis e da sua aplicação na indústria alimentar, como consequência do aumento do conhecimento sobre a ciência dos materiais e da tecnologia subjacente ao desenvolvimento de filmes e revestimentos comestíveis. Simultaneamente, associam-se a estes fatores o crescente interesse pela temática da sustentabilidade e $\mathrm{o}$ aumento da exigência dos consumidores, que procuram ativamente por alimentos com uma melhor qualidade e com um tempo de vida de prateleira superior, bem como alternativas mais ecológicas e biodegradáveis, em detrimento às embalagens convencionais, nomeadamente as embalagens de plástico (3, 5, 6, 10, 19-22).

Segundo Transparency Market Research, a procura por embalagens comestíveis pode aumentar 6,9\% anualmente até 2024 , e pode tornar-se num mercado com o valor de aproximadamente 2 biliões de euros anuais (23).

Atualmente, a nível global destacam-se empresas, entidades e centros de investigação que apostam no desenvolvimento destas embalagens. Em Portugal, é possível destacar alguns projetos com maior relevância no âmbito das embalagens biodegradáveis e comestíveis.

Destaca-se um dos projetos desenvolvido pela spinoff com ligação à Universidade do Minho, designada por Improveat, que desenvolveu soluções para alguns dos desafios da indústria alimentar, associados à perecibilidade dos alimentos (13).

Desenvolveram produtos como o BioCheeseCoat, que consiste em um revestimento comestível que prolonga o tempo de vida de prateleira de queijos em 50\%, inibe a contaminação por microorganismos patogénicos e previne a perda de água (14, 24); O BioNutriCoat foi desenvolvido com a finalidade de aumentar as propriedades nutricionais dos alimentos, nomeadamente de queijos, produtos de panificação e produtos cárneos, através da adição de vitaminas, antioxidantes, pré e probióticos (24); Por último, notabiliza-se ainda o BioFruitCoat, revestimento para hortofrutícolas, que aumenta o tempo de prateleira destes alimentos e previne a oxidação e degradação enzimática $(13,24,25)$.

No âmbito do projeto MultiBiorefinery, uma equipa de investigadores da Universidade de Coimbra, desenvolveu filmes de $\mathrm{N}$-carboxibutilquitosano com celulose, plastificantes (silicone ou glicerol) e antioxidante extraído do pinheiro (Pinus pinaster). Gaspar et al. utilizaram resíduos do sector agroalimentar e da pesca, particularmente a quitosana, para a elaboração do filme biodegradável (11).

Além da utilidade que a quitosana apresenta para as indústria das embalagens alimentares ecológicas, é relevante realçar que se trata de um polissacarídeo de grande importância devido à sua elevada disponibilidade na natureza $(11,26)$. Estima-se que o mercado global de quitina e quitosana poderá atingir 3,45 biliões de euros em 2021 
e apresentar uma Taxa de Crescimento Anual Composta (CAGR) de $15,4 \%$ (26).

A nível internacional, tome-se por exemplo a start-up NOTPLA, um projeto de Skipping Rocks Lab, cujo produto Ooho consiste em uma bolha comestível que encapsula água potável. Trata-se de uma membrana feita a partir de extrato de alga, e tem como finalidade eliminar as garrafas de plástico. Caso o invólucro não seja consumido, a membrana é biodegradável, decompondo-se em 4 a 6 semanas (18, 23, 27).

A empresa norte-americana Loliware, utilizou o alginato e o ágar, provenientes de algas, para a elaboração de palhinhas comestíveis, que atuam como o plástico durante 24 horas, depois de molhadas $(18,23)$. De realçar ainda a empresa Evoware, fundada na Indonésia, que produziu uma embalagem comestível à base de algas marinhas para um invólucro de hambúrguer e atualmente está a investir na produção de pequenas embalagens para temperos e café $(18,23)$.

\section{Matérias-Primas Usadas}

O desempenho das embalagens comestíveis depende dos materiais utilizados e de suas principais características, no que se refere às principais propriedades de revestimentos e filmes. Os materiais devem ser selecionados tendo em consideração o tipo de alimento a embalar, e as respetivas condições de armazenamento (15).

Os materiais usados para produzir embalagens comestíveis são geralmente polissacarídeos, proteínas e ceras que são capazes de formar um revestimento ou filme contínuo (6, 12, 23, 24, 28-30). A sua categorização depende do seu método de produção e origem. Estes incluem: materiais extraídos de fontes naturais (por exemplo, marinhas, agrícolas e animais), classificados como proteínas, polissacarídeos, ceras e lípidos; materiais produzidos por microrganismos, como polissacarídeos e alguns compostos ativos (Figura 1) $(28,31)$.

Existem ainda, os aditivos de filme, que correspondem a materiais diferentes dos formadores de filme, tais como as biomoléculas, que são incorporados nas matrizes, com o intuito de melhorar e controlar as propriedades menos interessantes de alguns materiais. Exemplos destes são os plastificantes, emulsificantes, agentes antimicrobianos (ex.: óleos essenciais extraídos de plantas), e antioxidantes (5, 6, 10, 20, 28, 30, 32-34)

Exemplos de polissacarídeos usados na concretização de embalagens comestíveis são: a celulose e os seus derivados, obtidos a partir de plantas ou microorganismos, e a pectina e a galactomanana extraída de plantas $(2,6,8-10,15,28,29,32,35)$. Outros exemplos são o alginato e carragenina, provenientes de algas e produzidos por microorganismos (5, 7-9). Como polissacarídeo de fonte animal, destacam-se a quitina e a quitosana, esta última resulta da desacetilação da quitina, provenientes de insetos e crustáceos. De notar que, a maioria dos polissacarídeos são solúveis em água e os filmes destas biomoléculas, exibem boas propriedades mecânicas e constituem uma barreira contra gases e lípidos, mas oferecem pouca resistência à migração de água. Semelhante a outros filmes hidrofílicos, a humidade afeta as suas propriedades funcionais $(5,6,36,37,9,11,15,28,30,32,34,35)$.

Os filmes à base de proteínas constituem excelentes barreiras contra 0 transporte de $\mathrm{O}_{2}, \mathrm{CO}_{2}$, aromas e lípidos, no entanto apresentam uma elevada permeabilidade ao vapor de água. A barreira e as propriedades mecânicas dos filmes de proteína são comprometidas pela humidade devido à sua natureza hidrofilica. Exemplos de proteínas usadas são o glúten de trigo, proteína de milho - Zein e proteína de soja isolada (4, 6 , $8-10,28,30,32,38)$. No caso de proteínas de origem animal temos o colagénio, vastamente utilizado na produção do invólucro de salsichas, e a gelatina, obtida através da hidrólise do colagénio $(5,8,39)$. Além disso, as proteínas do leite podem ser usadas para a elaboração de filmes edíveis, tais como a caseína e a proteína do soro do leite (6, 8-10, 28, 30, 32, 34, 38).

No que concerne à utilização de materiais lipídicos, estes têm sido

\section{Figura 1}

Classificação e origem de filmes e revestimentos comestíveis $(3,9,12,28,32)$

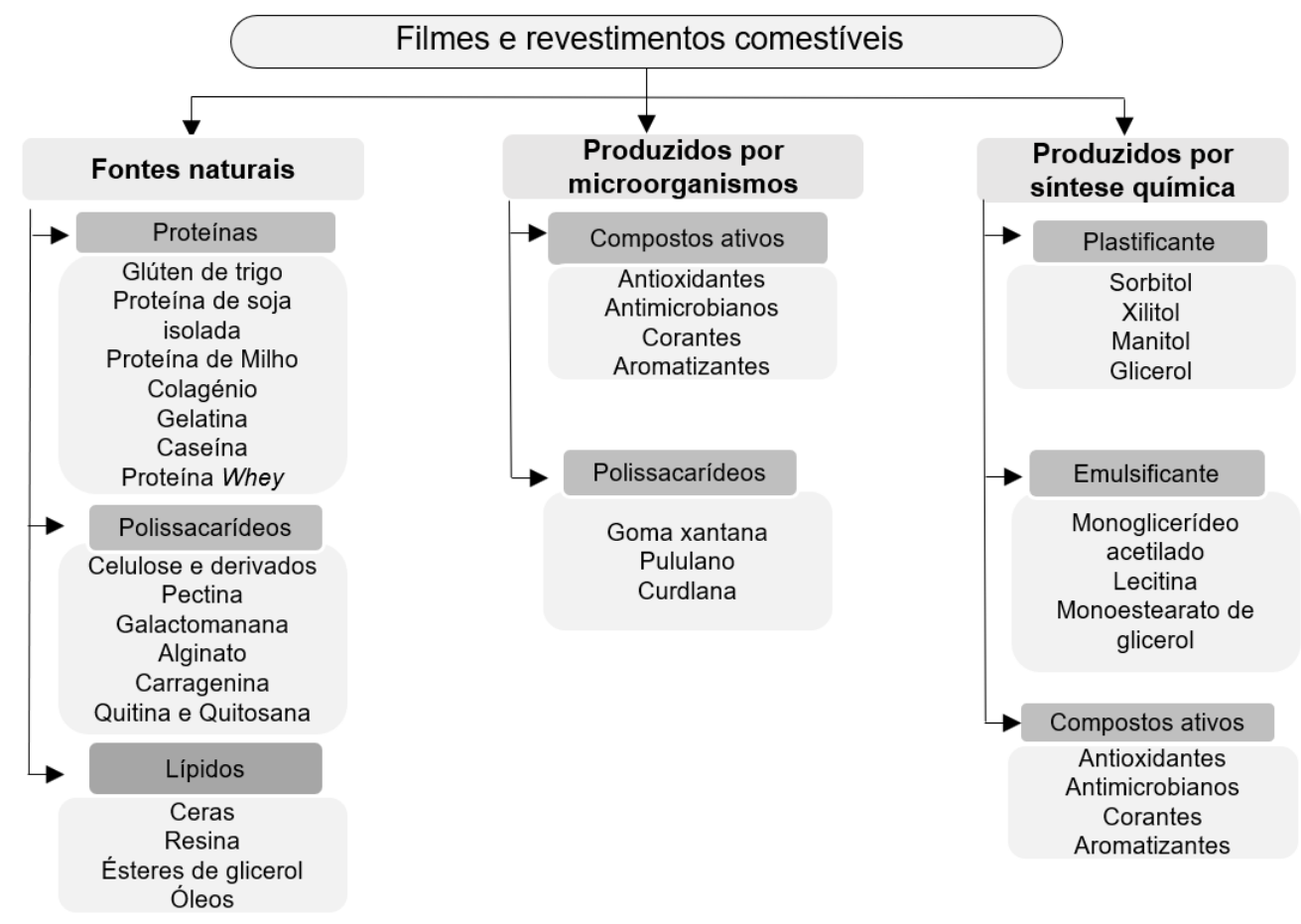


amplamente utilizados como revestimentos protetores contra a transferência de humidade e para adicionar brilho. Contrariamente às outras macromoléculas, os compostos lipídicos não têm um grande número de unidades de repetição conectadas por ligações covalentes para formar uma estrutura molecular, apresentando alguma fragilidade, não formando estruturas coesivas e autossustentáveis. Existem desvantagens de empregar lípidos em materiais de embalagem comestíveis, tais como o sabor e textura de cera, a superfície oleosa e a potencial rancificação. Neste âmbito, é possível destacar as ceras, a resina e ésteres do glicerol, como moléculas usadas na produção de filmes e revestimentos comestíveis $(6,10,28,32,34)$.

\section{Aspeto Tecnológico - Efeitos nos Alimentos}

As condições químicas, ambientais e o stress, ao qual o alimento está sujeito ao longo da cadeia alimentar, podem influenciar o desempenho da barreira dos filmes e revestimentos comestíveis (24).

Tal como supracitado, vários compostos ativos com propriedades distintas, podem ser adicionados à matriz dos revestimentos ou filmes comestíveis (24). Por exemplo, corantes adicionados aos materiais comestíveis podem melhorar a aparência de alguns géneros alimentícios durante o armazenamento. Verificou-se que filmes comestíveis feitos com goma xantana, lactato de cálcio e a-tocoferol intensificaram a cor laranja das cenouras e diminuíram a descoloração durante 3 semanas, aquando do período de armazenamento (40).

Em relação ao valor nutricional dos alimentos, a utilização do revestimento de goma xantana anteriormente descrito, permitiu manter o conteúdo de $\beta$-caroteno e aumentou o teor de vitamina $E$ e de cálcio nas cenouras, durante o armazenamento (40).

A aplicação de revestimentos de quitosana em morangos e framboesas demonstrou aumentar a vida de prateleira e o valor nutricional, em condições de temperatura de $2^{\circ} \mathrm{C}$ e humidade relativa de $88 \%$, durante 3 semanas, bem como em temperaturas negativas de $-23^{\circ} \mathrm{C}$ até 6 meses, devido à capacidade de inibição do crescimento fúngico deste polissacarídeo (41). Além disso, a evidência sugere que a quitosana apresenta caraterísticas bactericidas e apresenta-se como um excelente revestimento para frutas e hortícolas $(37,41-45)$.

Existem produtos frágeis que podem melhorar suas propriedades mecânicas através do uso de revestimentos comestíveis $(25,44)$. Exemplos destes são o uso de revestimento de quitosana aplicado em morangos para diminuir os danos mecânicos durante o armazenamento, processamento e transporte da fruta (44).

No entanto, as embalagens comestíveis à base de hidratos de carbono e proteínas têm menos resistência à tensão, devido à sua elevada densidade energética coesiva, o que leva a que a sua elasticidade seja menor. Esta característica pode ser usada para fornecer uma camada externa protetora tipo "casca dura" para alguns produtos. Os plastificantes que podem ser usados nesses filmes incluem sorbitol, xilitol, manitol e glicerol (40, 44, 46).

Os revestimentos comestíveis também podem aumentar o sabor e a aparência do produto, por exemplo, as ceras são usadas para adicionar uma aparência brilhante em limões, laranjas e maçãs (40, 44, 46).

Como exemplo da aplicação de embalagens comestíveis em alimentos lácteos, Miguel Ângelo Cerqueira, cofundador da start-up Improveat, verificou que o revestimento de galactomanana juntamente associado a uma temperatura de armazenamento de $4^{\circ} \mathrm{C}$, demonstrou aumentar o tempo de prateleira do queijo e diminuir a transferência de gases, pelo que pode constituir uma alternativa promissora aos revestimentos existentes à base de petróleo que são usados na proteção de superfícies de queijo (47).

A aplicação de revestimentos comestíveis pode ser considerada uma potencial abordagem para preservar a qualidade de pescado, que se apresenta como um alimento extremamente perecível $(36,43,48)$. O revestimento de alginato enriquecido com 6-gingerol, composto químico com propriedades antioxidantes e antimicrobianas, demonstrou diminuir a oxidação lipídica, a degradação de proteínas e a quebra de nucleotídeos, que estavam associados à deterioração do pescado durante o armazenamento, desta forma foi possível aumentar o tempo de prateleira do goraz (Pagrosomus major) até 20 dias à temperatura de $4 \pm 1^{\circ} \mathrm{C}$ (48).

Relativamente a produtos cárneos, Cardoso et al. verificaram que os revestimentos mono e bicamada de gelatina-quitosana prolongaram a vida útil da carne bovina de 6 para 10 dias, durante o armazenamento no retalho alimentar, sujeita a exposição de luz, uma vez que retardaram a oxidação lipídica e o crescimento de bactérias psicrófilas, fungos e leveduras (49).

É ainda, importante reforçar que como os materiais de embalagem são seguros para consumo humano, a transmissão das moléculas de embalagem para os alimentos não se traduz em qualquer problema de saúde (50)

\section{A Aceitabilidade dos Filmes e Revestimentos Comestíveis}

A aceitação de filmes comestíveis pelo consumidor depende de fatores tais como propriedades funcionais, a aparência da embalagem, propriedades organoléticas, marketing alimentar, preço, entre outros fatores. É importante salientar que as películas e embalagens comestíveis não devem afetar as propriedades nutricionais e organoléticas dos alimentos embalados nestas condições. Devem aparentar ser transparentes e sem odor e sabor. No entanto podem auxiliar a realçar o sabor, cor e aspeto do alimento (50-52).

A falta de conhecimento e o receio em consumir este tipo de embalagens pode reduzir a sua aceitação. Desta forma, é necessário desenvolver estratégias de marketing, programas de sensibilização, reduzir os preços dos alimentos condicionados com estas embalagens, publicitar e apresentar ofertas atrativas, de modo a promover o consumo destes alimentos (50)

É relevante conhecer o perfil do consumidor, uma vez que filmes edíveis, extraídos de subprodutos de origem animal, podem não ser aceites por vegetarianos e por indivíduos de determinadas religiões (50).

De notar que, os filmes e revestimentos comestíveis podem conter algum alergénio, que pode desencadear uma resposta alérgica a consumidores suscetíveis, pelo que alguns indivíduos podem não aceitar este tipo de embalagens. É essencial que as autoridades reguladoras enfatizem a necessidade de os produtores rotularem estas embalagens e informar os consumidores sobre a presença de alergénios e de ingredientes de origem animal $(8,51)$.

Embora haja uma maior consciência por parte de alguns consumidores sobre o tema da sustentabilidade, a maior parte destes têm um maior interesse em propriedades que lhes proporcionam benefício, e os benefícios ambientais e industriais dos produtos muitas vezes constituem prioridades secundárias $(50,52)$.

Adicionalmente, o custo é um fator determinante para a aceitação de filmes comestíveis, que atualmente têm um custo muito superior aos filmes de plástico derivados do petróleo. Porém, como a produção de filmes comestíveis está em fase de desenvolvimento, e menos quantidades são produzidas, o alto custo dos filmes comestíveis não pode ser tomado como um ponto negativo no momento. O custo total da embalagem deve ser inferior a 10\% do custo do produto. Análises de custo-benefício adequadas devem ser realizadas para justificar a adaptação de filmes edíveis $(52,53)$. 


\section{Sustentabilidade de Filmes e Revestimentos Comestíveis}

Os polímeros derivados de petróleo têm dominado as indústrias de embalagens, constituindo $37 \%$ do mercado total de materiais de embalagem para alimentos $(2,54)$. Anualmente, mais de 8 milhões de toneladas de resíduos de plástico entram no oceano, e estima-se que as embalagens plásticas representam a maior porção deste conteúdo (55). Tratam-se de substâncias não comestíveis e nocivas, que estão a ser consumidas pela vida marinha, e consequentemente, por humanos, embora indiretamente, através da cadeia alimentar, na forma de microplásticos. Alguns investigadores apontam para o facto de os plásticos conterem substâncias carcinogénicas, nomeadamente bisfenol A (BPA) e poli(cloreto de vinilo) (PVC) (56).

A embalagem comestível é feita de ingredientes consumíveis para humanos, que pode ser consumida juntamente com a comida e bebida, pelo que o problema de descarte de resíduos é praticamente inexistente. Tal como anteriormente referido, ainda que acabe por não ser consumido, degrada-se mais rápido comparativamente a materiais sintéticos (56).

Outro ponto positivo, é o facto de muitos filmes e revestimentos utilizarem subprodutos, como por exemplo, o colagénio, que existe principalmente em peles de animais, músculos, ossos e tecidos conjuntivos $(4,38)$. Outro exemplo, é a utilização de quitina, presente no exoesqueleto de crustáceos, insetos e em outros materiais biológicos (ex.: Paredes fúngicas) $(3,11)$.

De acordo com os relatórios da Food and Agriculture Organization (FAO), $14 \%$ dos alimentos produzidos globalmente são desperdiçados durante a fase de produção pós-colheita, consequência da redução da vida útil e do amadurecimento das frutas antes do seu consumo. Estas frutas podem ser convertidas em produtos economicamente importantes, como materiais para embalagem comestíveis, que podem desempenhar um papel decisivo na melhoria da vida útil dos alimentos (57). Por exemplo, são utilizadas polpas de frutas para extrair biomoléculas, nomeadamente a pectina e a celulose $(5,11,58)$. Desta forma, há um maior aproveitamento destes ingredientes, e consequentemente, uma redução do desperdício alimentar, que constitui um problema ético, socioeconómico e ambiental $(6,8,59)$.

\section{Embalagens Comestíveis e Segurança Alimentar}

De acordo com o Regulamento da UE (EC) N. ${ }^{\circ}$ 1935/2004, todos os materiais e artigos em contato com alimentos não devem colocar em risco a saúde humana, alterar a composição dos alimentos de uma forma inaceitável, e alterar o sabor, odor ou textura dos alimentos (60). De acordo com este regulamento, os materiais serão autorizados para o embalamento de alimentos, somente, se nenhum risco à saúde humana for evidenciado. No entanto, a avaliação de segurança sobre a inclusão de nanomateriais em embalagens de alimentos e seus efeitos toxicológicos não são mencionados claramente no presente regulamento (60).

Além disso, cada país pode ter uma lista diferente de materiais aprovados adequados para a produção de filmes comestíveis. Portanto, os fabricantes de alimentos que exportam os seus produtos para outros países devem considerar as regulamentações de diferentes países e o filme deve ser formado com os materiais listados na lista de materiais alimentares aprovados $(8,50)$.

A Food and Drug Administration (FDA), estabeleceu o conceito de Generally Recommended As Safe (GRAS), para classificar a segurança de substâncias, pelo que o termo abrange materiais utilizados para a elaboração de embalagens comestíveis, desde que respeitam as normas de boas práticas de higiene e segurança alimentar e a evidência cientifica sugere a sua segurança para a sua inclusão em filmes e revestimentos edíveis $(8,12,16,18,28,54,61)$. De salientar ainda, que este reconhecimento não garante total segurança do produto, principalmente para consumidores com alergias ou sensibilidades alimentares, tais como intolerância à lactose e doença celíaca $(8,16$, 28).

\section{Desafios da Comercialização de Embalagens Comestíveis}

Quando comparados a plásticos sintéticos, os filmes edíveis apresentam des-vantagens, no âmbito da resistência mecânica, pois não apresentam elevada elasticidade, além disso têm uma baixa resistência a gases e líquidos, e um custo elevado (50).

É necessário que os filmes e embalagens comestíveis cumpram alguns requisitos, como excelentes qualidades sensoriais, devem constituir uma barreira protetora para os géneros alimentícios, ter uma elevada resistência mecânica, elevada estabilidade microbiana, isenta de agentes patogénicos, tóxicos e toxinas, seguro para a saúde, não poluentes e de baixo custo. A produção de filmes comestíveis ocorre maioritariamente em laboratórios, pelo que, há algumas limitações a serem ultrapassadas para o sucesso comercial de filmes e revestimentos comestíveis $(15,50)$.

\section{ANÁLISE CRÍTICA E CONCLUSÕES}

Atendendo ao objetivo previamente definido, foi possível distinguir os conceitos de filme e revestimento comestível, caracterizar o impacto ambiental e tecnológico das embalagens comestíveis, a aplicabilidade dos filmes e revestimentos, e o tipo de matérias-primas utilizadas, atendendo aos diferentes tipos e grupos de alimento a embalar. Além disso, foi possível explorar as possíveis implicações na segurança alimentar, bem como a aceitabilidade por parte dos consumidores e da indústria alimentar.

As vantagens exclusivas e a versatilidade dos materiais de embalagens comestíveis são concebidas para criar embalagens sustentáveis e inovadoras para reduzir o desperdício alimentar, através da utilização de subprodutos, e melhorar a estabilidade, qualidade, segurança, $e$ conveniência dos produtos embalados, diminuindo consequentemente as perdas de alimento ao longo da cadeia alimentar.

No entanto, a maioria das aplicações destes materiais tem sido conduzida maioritariamente à escala laboratorial, pelo que é necessário realizar mais pesquisas de forma a transferir e aplicar as informações recolhidas a nível laboratorial para a escala comercial, e intensificar a sua produção e reconhecimento pela indústria alimentar.

\section{REFERÊNCIAS BIBLIOGRÁFICAS}

1. Beyer R. Manual on food packaging for small and medium-size enterprises in Samoa. $2012 ; 74$.

2. Kumar S, Mukherjee A, Dutta J. Chitosan based nanocomposite films and coatings: Emerging antimicrobial food packaging alternatives. Trends Food Sci Technol. 2020;97(August 2019):196-209.

3. Mohamed SAA, El-Sakhawy M, El-Sakhawy MAM. Polysaccharides, Protein and Lipid -Based Natural Edible Films in Food Packaging: A Review. Carbohydr Polym [Internet]. 2020;238:116178. Available from: https://doi.org/10.1016/j.carbpol.2020.116178.

4. Etxabide A, Uranga J, Guerrero P, de la Caba K. Development of active gelatin films by means of valorisation of food processing waste: A review. Food Hydrocoll [Internet]. 2017;68:192-8. Available from: http://dx.doi.org/10.1016/j.foodhyd.2016.08.021. 5. Otoni CG, Avena-Bustillos RJ, Azeredo HMC, Lorevice M V., Moura MR, Mattoso LHC, et al. Recent Advances on Edible Films Based on Fruits and Vegetables-A Review. Compr Rev Food Sci Food Saf. 2017 Sep 1;16(5):1151-69.

6. Al-Tayyar NA, Youssef AM, Al-Hindi RR. Edible coatings and antimicrobia nanoemulsions for enhancing shelf life and reducing foodborne pathogens of fruits and vegetables: A review. Sustain Mater Technol [Internet]. 2020;26:e00215. Available from: https://doi.org/10.1016/.susmat.2020.e00215. 
7. Singh $P$, Baisthakur $P$, Yemul OS. Synthesis, characterization and application of crosslinked alginate as green packaging material. Heliyon [Internet]. 2020;6(1):e03026. Available from: https://doi.org/10.1016/j.heliyon.2019.e03026.

8. Dubey NK, Dubey R. Edible films and coatings: An update on recent advances. In: Biopolymer-Based Formulations: Biomedical and Food Applications [Internet]. Elsevier Inc.; 2020. p. 675-95. Available from: http://dx.doi.org/10.1016/B978-0-12-8168974.00027-8.

9. Ramos ÓL, Pereira RN, Cerqueira MA, Martins JR, Teixeira JA, Malcata FX, et al. Biobased Nanocomposites for Food Packaging and Their Effect in Food Quality and Safety. In: Food Packaging and Preservation [Internet]. Elsevier Inc.; 2018. p. 271-306. Available from: http://dx.doi.org/10.1016/B978-0-12-811516-9/00008-7.

10. Siracusa V, Rosa MD. Sustainable Packaging. In: Sustainable Food Systems from Agriculture to Industry [Internet]. Elsevier Inc.; 2018. p. 275-307. Available from: http:// dx.doi.org/10.1016/B978-0-12-811935-8.00008-1.

11. Gaspar MC, Leocádio J, Mendes CVT, Cardeira M, Fernández N, Matias A, et al. Biodegradable film production from agroforestry and fishery residues with active compounds. Food Packag Shelf Life. 2021;28.

12. Salgado PR, Ortiz CM, Musso YS, Di Giorgio L, Mauri AN. Edible films and coatings containing bioactives. Curr Opin Food Sci [Internet]. 2015;5:86-92. Available from: http:// dx.doi.org/10.1016/j.cofs.2015.09.004

13. Grumezescu AM, Holban AM, editors. Food Packaging and Preservation. In Academic Press Elsevier; 2018 [cited 2020 Nov 29]. p. 39-40. Available from: https:// books.google.pt/.books? $\mathrm{id}=\mathrm{dHzGDgAAQBAJ} \& p g=P A 40 \& l p g=P A 40 \& d q=$ bionutricoat\&source=bl\&ots=1UldHr6Y9V\&sig=ACfU3U1 hzh7vhy0J0h2lwbF_imuQhCFmog\&hl=pt-PT\&sa=X\&ved=2ahUKEwinioL_sqftAhWOT8AKHdsWAKEQ6AEwEHoE

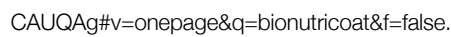

14. Costa MJ, Maciel LC, Teixeira JA, Vicente AA, Cerqueira MA. Use of edible films and coatings in cheese preservation: Opportunities and challenges. Food Res Int [Internet]. 2018;107:84-92. Available from: https://doi.org/10.1016/j.foodres.2018.02.013. 15. Cerqueira MÂPR. Edible packaging. Encycl Food Chem. 2018;173-6.

16. Pavlath AE, Orts W. Edible Films and Coatings for Food Applications. Edible Film Coatings Food Appl. 2009;1-23.

17. Mkandawire M, Aryee AN. Resurfacing and modernization of edible packaging material technology. Curr Opin Food Sci [Internet]. 2018;19:104-12. Available from: https:// doi.org/10.1016/j.cofs.2018.03.010.

18. Katiyar V, Ghosh T. Nanotechnology in Edible Food Packaging: Food Preservation Practices for a Sustainable Future [Internet]. Springer Nature Singapore Pte Ltd.; 2021 [cited 2021 Jun 8]. 1-137 p. Available from: https://books.google.pt/books?hl=pt-PT\&l$r=\& i d=C O U f E A A A Q B A J \& o i=f n d \& p g=P R 5 \& d q=$ "Edible+Food+packaging"\&ots=yAHtaUUHmo\&sig=uHPTBzQeNf6vLRq2cVuscQ0T2sA\&redir_esc=y\#v=onepage\&q="Edible Food packaging" $\&$ f=false.

19. Cerqueira MÂPR, Pereira RNC, Ramos ÓL da S, Teixeira JAC, Vicente AA. Edible Food Packaging: Materials and Processing Technologies [Internet]. CRC Press; 2016 [cited 2020 Nov 29]. Available from: https://books.google.pt/books?hl=pt-PT\&l$r=\& i d=g f 9 O D A A A Q B A J \& o i=f n d \& p g=P P 1 \& d q=$ portugal+edible+packaging\&ots=gBpsbdjXjf\&sig=O21uKiN3vlONVxKOKCpgwO-XkEs\&redir_esc=y\#v=onepage\&q=portugal edible packaging $\&=$ false.

20. Hashemi SMB, Mousavi Khaneghah A. Characterization of novel basil-seed gum active edible films and coatings containing oregano essential oil. Prog Org Coatings [Internet] 2017;110(April):35-41. Available from: http://dx.doi.org/10.1016/..porgcoat.2017.04.041. 21. Wang Y, Zhang R, Ahmed S, Qin W, Liu Y. Preparation and characterization of corn starch bio-active edible packaging films based on zein incorporated with orange-peel oil. Antioxidants. 2019;8(9).

22. Gallego MG, Gordon MH, Segovia F, Almajano Pablos MP. Gelatine-based antioxidant packaging containing Caesalpinia decapetala and tara as a coating for ground beef patties. Vol. 5, Antioxidants. 2016.

23. Patel P. Edible Packaging. ACS Cent Sci. 2019 Dec 26;5(12):1907-10. 24. Aguirre-Joya JA, De Leon-Zapata MA, Alvarez-Perez OB, Torres-León C, Nieto-Oropeza DE, Ventura-Sobrevilla JM, et al. Basic and Applied Concepts of Edible Packaging for Foods. In: Food Packaging and Preservation. Elsevier; 2018. p. 1-61.
25. Pereira AC. Development of new coatings for raspberries. University of Minho - Biological Engineering Center; 2016

26. Díaz-Montes E, Castro-Muñoz R, Almeida De Sousa M. Trends in Chitosan as a Primary Biopolymer for Functional Films and Coatings Manufacture for Food and Natural Products. Polymers (Basel) [lnternet]. 2021; Available from: https://doi.org/10.3390/ polym13050767.

27. Boonchujaras A, Furulund K. Would you eat it? An investigation of how perceived sustainability and perceived risk influence consumer acceptance of edible food packaging. Navn: [Internet]. BI Oslo Thesis; 2010. Available from: papers2://publication/uuid/3B35CDAD-4E3A-4C3C-B3D7-2DA83D3ED2B3.

28. Janjarasskul T, Krochta JM. Edible packaging materials. Annu Rev Food Sci Technol. 2010;1(1):415-48.

29. Sampathkumar K, Tan KX, Loo SCJ. Developing Nano-Delivery Systems for Agriculture and Food Applications with Nature-Derived Polymers. iScience [Internet]. 2020;23(5):101055. Available from: https://doi.org/10.1016/j.isci.2020.101055.

30. Çakmak H, Özselek Y, Turan OY, Fıratlıgil E, Karbancioğlu-Güler F. Whey protein isolate edible films incorporated with essential oils: Antimicrobial activity and barrier properties. Polym Degrad Stab [Internet]. 2020; Available from: https://doi.org/10.1016/j. polymdegradstab.2020.109285.

31. Flôres SH, Rios A de O, lannke AOS, de Campo C, Vargas CG, Santos CDM, et al. Films for Food From Ingredient Waste. Ref Modul Food Sci. 2017.

32. Trinetta V, Ecolab R. Edible Packaging [Internet]. Reference Module in Food Science. Elsevier; 2016. 1-4 p. Available from: http://dx.doi.org/10.1016/B978-0-08-100596-5.03210-8. 33. Nisar T, Wang ZC, Yang X, Tian Y, lqbal M, Guo Y. Characterization of citrus pectin films integrated with clove bud essential oil: Physical, thermal, barrier, antioxidant and antibacterial properties. Int J Biol Macromol [Internet]. 2018;106:670-80. Available from: http://dx.doi.org/10.1016/j.jibiomac.2017.08.068.

34. Díaz-Montes E, Castro-Muñoz R. Edible Films and Coatings as Food-Quality Preservers: An Overview. 2021; Available from: https://dx.doi.org/10.3390/foods10020249. 35. Sahraee S, Milani JM, Regenstein JM, Kafil HS. Protection of foods against oxidative deterioration using edible films and coatings: A review. Food Biosci. 2019;32(July). 36. Yu D, Regenstein JM, Xia W. Bio-based edible coatings for the preservation of fishery products: A Review. Crit Rev Food Sci Nutr [Internet]. 2019;59(15):2481-93. Available from: https://doi.org/10.1080/10408398.2018.1457623.

37. Yuan G, Chen X, Li D. Chitosan films and coatings containing essential oils: The antioxidant and antimicrobial activity, and application in food systems [Internet]. Vol. 89, Food Research International. Elsevier B.V.; 2016. 117-128 p. Available from: http:// dx.doi.org/10.1016/j.foodres.2016.10.004.

38. Langmaier F, Mokrejs P, Kolomaznik K, Mladek M. Biodegradable packing materials from hydrolysates of collagen waste proteins. Waste Manag. 2008;28(3):549-56. 39. Wang Y, Zhang R, Qin W, Dai J, Zhang Q, Lee KJ, et al. Physicochemical properties of gelatin films containing tea polyphenol-loaded chitosan nanoparticles generated by electrospray. Mater Des [Internet]. 2020;185:108277. Available from: https://doi. org/10.1016/j.matdes.2019.108277.

40. Mei Y, Zhao Y, Yang J, Furr HC. Using Edible Coating to Enhance Nutritional and Sensory Qualities of Baby Carrots. J Food Sci [Internet]. 2002 Jun 1 [cited 2020 Oct 8];67(5):1964-8. Available from: http://doi.wiley.com/10.1111/j.1365-2621.2002.tb08753.x.

41. Han C, Zhao Y, Leonard SW, Traber MG. Edible coatings to improve storability and enhance nutritional value of fresh and frozen strawberries (Fragaria $x$ ananassa) and raspberries (Rubus ideaus). Postharvest Biol Technol. 2004;33(1):67-78.

42. Pavinatto A, de Almeida Mattos AV, Malpass ACG, Okura MH, Balogh DT, Sanfelice RC. Coating with chitosan-based edible films for mechanical/biological protection of strawberries. Int J Biol Macromol [Internet]. 2020;151:1004-11. Available from: https://doi. org/10.1016/j.jjbiomac.2019.11.076.

43. Cai L, Li X, Wu X, Lv Y. Effect of Chitosan Coating Enriched with Ergothioneine on Quality Changes of Japanese Sea Bass ( Lateolabrax japonicas ). 2013.

44. Han C, Lederer C, McDaniel M, Zhao Y. Sensory Evaluation of Fresh Strawberries (Fragaria ananassa) Coated with Chitosan-based Edible Coatings. J Food Sci [Internet]. 2006 May 31 [cited 2020 Oct 8];70(3):S172-8. Available from: http://doi.wiley. com/10.1111/j.1365-2621.2005.tb07153.x. 
45. Pinzon M, Garcia O, Villa C. The influence of Aloe Vera gel incorporation on the physicochemical and mechanical properties of Banana Starch-chitosan Edible Films. J Sci Food Agric. 2018;28(3).

46. A. Pascall M. The Application of Edible Polymeric Films and Coatings in the Food Industry. J Food Process Technol. 2012;04(02)

47. Cerqueira MÂPR. Desenvolvimento e Caracterização de Novos Revestimentos Edíveis para a Preservação da Qualidade de Queijos. Universidade do Minho; 2010.

48. Cai L, Wang Y, Cao A, Lv Y, Li J. Effect of alginate coating enriched with 6-gingerol on the shelf life and quality changes of refrigerated red sea bream (Pagrosomus major) fillet. RSC Adv [Internet]. 2015;5:36882-9. Available from: http://dx.doi.org/10.1039/ C5RA04551G.

49. Cardoso GP, Andrade MPD, Rodrigues LM, Massingue AA, Fontes PR, Ramos A de LS, et al. Retail display of beef steaks coated with monolayer and bilayer chitosan-gelatin composites. Meat Sci [Internet]. 2019;152(November 2018):20-30. Available from: https://doi.org/10.1016/..meatsci.2019.02.009.

50. Jeya Jeevahan J, Chandrasekaran M, Venkatesan SP, Sriram V, Britto Joseph G, Mageshwaran G, et al. Scaling up difficulties and commercial aspects of edible films for food packaging: A review. Trends Food Sci Technol. 2020;100(February):210-22.

51. Wan VCH, Lee CM, Lee SY. Understanding consumer attitudes on edible films and coatings: Focus group findings. J Sens Stud. 2007;22(3):353-66.

52. Aldred Cheek K, Wansink B. Making It Part of the Package: Edible Packaging Is More Acceptable to Young Consumers When It Is Integrated With Food. J Food Prod Mark [Internet]. 2017;23(6):723-32. Available from: http://dx.doi.org/10.1080/104544 46.2017.1244793.

53. Mihindukulasuriya SDF, Lim LT. Nanotechnology development in food packaging: A review. Trends Food Sci Technol. 2014 Dec 1;40(2):149-67.

54. Anis A, Pal K, Al-Zahrani SM. Essential Oil-Containing Polysaccharide-Based Edible Films and Coatings for Food Security Applications. 2021; Available from: https://doi. org/10.3390/polym13040575.

55. MacArthur DE, Waughray D, Stuchtey M. The New Plastics Economy: Rethinking the future of plastics. World Economic Forum. 2016.

56. Rashid S. Edible Cutleries as Sustainable Substitute for Plastic Cutleries. Brac University; 2019.

57. Susmitha A, Sasikumar K, Rajan D, Padmakumar M A, Nampoothiri KM. Development and characterization of corn starch-gelatin based edible films incorporated with mango and pineapple for active packaging. Food Biosci. 2021;41(March).

58. Matheus JRV, Miyahira RF, Fai AEC. Biodegradable films based on fruit puree: a brief review. Crit Rev Food Sci Nutr [Internet]. 2020;0(0):1-8. Available from: https://doi.org/1 0.1080/10408398.2020.1772715.

59. Bhargava N, Sharanagat VS, Mor RS, Kumar K. Active and intelligent biodegradable packaging films using food and food waste-derived bioactive compounds: A review. Trends Food Sci Technol [Internet]. 2020;105:385-401. Available from: https://doi. org/10.1016/j.tifs.2020.09.015.

60. Comissão Europeia. Regulamento (CE) No 1935/2004. J Of da União Eur. 2004;4-17. 61. Adiletta G, Matteo M Di, Petriccione M. Multifunctional Role of Chitosan Edible Coatings on Antioxidant Systems in Fruit Crops: A Review. Int J Mol Sci [Internet]. 2021; Available from: https://doi.org/10.3390/ijms22052633. 